\title{
The effects of hesperidin or naringin dietary supplementation on yoghurt quality parameters in dairy ewes - A preliminary study
}

Panagiotis Simitzis ${ }^{1 *}$ Theofilos Massouras ${ }^{2}$ Michael Goliomytis ${ }^{1}$ Maria Charismiadou ${ }^{1}$ Katerina Moschou ${ }^{2}$, Christina Economou $^{1}$ Vagelis Papadedes ${ }^{1}$, Sofia Lepesioti ${ }^{1}$ and Stelios Deligeorgis ${ }^{1}$

${ }^{1}$ Department of Animal Production, Laboratory of Animal Breeding and Husbandry, Agricultural University of Athens, Iera Odos 75, 11855 Athens, Greece

${ }^{2}$ Department of Food Science and Human Nutrition, Laboratory of Dairy Science and Technology, Agricultural University of Athens, Iera Odos 75 , 11855 Athens, Greece

${ }^{*}$ Corresponding author: Dr. Panagiotis Simitzis, Department of Animal Production, Laboratory of Animal Breeding and Husbandry, Agricultural University of Athens, Iera Odos 75, 11855 Athens, Greece; TEL: +302105294427, 14; FAX: +302105294442; E-MAIL: pansimitzis@aua.gr

Received: December 11, 2019; Accepted: December 12, 2019; Published: December 25, 2019

\begin{abstract}
Stakeholders that are involved in the animal production chain, such as primary producers,processors, distributors, and retailers continuously seek for alternative ways of improving health benefits and technological properties of dairy products. Hesperidin and naringin belong to flavonoids and are well-known for their multifaceted properties. The aim of this preliminary study was therefore to examine the effects of flavonoids supplementation into the diets of dairy ewes on the quality parameters and oxidative stability of yoghurt manufactured by their milk. Thirty-six Chios ewes were allocated to four groups; the control group (C) was fed concentrates without supplementation, while the other three experimental groups received the same diet further supplemented with hesperidin $(6000 \mathrm{mg} / \mathrm{kg})$, naringin $(6000 \mathrm{mg} / \mathrm{kg})$, or $\alpha$-tocopheryl acetate $(200 \mathrm{mg} / \mathrm{kg})$. As indicated, no effects on yoghurt quality parameters and oxidative stability were observed in individual samples manufactured from milk collected after 7, 21 and 28 days of flavonoids dietary supplementation. In conclusion, inclusion of flavonoids in ewes' diet does not appear to affect yoghurt quality characteristics.
\end{abstract}

Keywords: hesperidin; naringin; yoghurt quality; oxidative stability 31

\section{Introduction}

Dairy fermented foods, such as yoghurt, have gained a positive perception and enjoyed high popularity among the consumers due to their beneficial effects on human health [1]. Among others, consumption of these products improves immunity and results in a slight reduction in stomach $\mathrm{pH}$ that minimizes the risk of pathogen transit and the impacts of low gastric juice secretion [2]. At the same time, several peptides derived by proteolysis could lower blood pressure in hypertensive patients [3]. Yoghurt consists of a casein network aggregated through isoelectric precipitation by lactic acid bacteria, such as Streptococcus thermophilus and Lactobacillus delbrueckii spp. bulgaricus. Fermentation is a chemical process in which specific enzymes break down organic substances into smaller compounds resulting in more digestible, stable and flavored foods with enhanced nutritional value [4]. Enrichment of animal products with natural bioactive compounds seems to improve their quality characteristics and fortifies consumers against oxidation effects. Dietary flavonoids have received significant attention in recent years due to their antioxidant, anti-inflammatory, anti-mutagenic and anti-clotting properties that are associated with a declined risk of cardiovascular diseases and cancer development $[5,6]$. In general, levels of polyphenols in yoghurt are low and its enrichment with plant- derived additives could improve its phenolic content contributing in disease prevention and correction of deficiencies with minimal side effects [1].

Several pre- and post- fermentation approaches for adding polyphenols to yoghurt have already been implemented with positive effects on the derived product. Addition of polyphenols originated from bitter orange (Citrus aurantium 1.) flowers [7], berry [8], apple [9], strawberry [10], green tea [11], peppermint, dill and basil [12], pomegranate peel [13] or juice [14], or grape seed [15] significantly increased yoghurt antioxidant capacity without other significant effects on its quality. According to the literature [16], the pre-fermentation application could introduce some advantages such as the promotion of starter cultures'growth. Alternative approaches are continuously evaluated in animal production systems with the intention to improve the nutritional value and the organoleptic properties of the derived products. However, no data exist describing the effects of flavonoids inclusion into the diets of dairy ewes on the quality of the derived yoghurt. The aim of the present study was therefore to investigate the effects of hesperidin or naringin or a-tochopheryl acetate dietary supplementation on the quality characteristics (colour, $\mathrm{pH}$, syneresis and texture) and oxidative stability of yoghurt manufactured by ewe milk. 


\section{Methods \& Materials}

\section{Animal and diets}

The experimental design is described in detail by Simitzis et al. [17]. In brief, 36 lactating Chios ewes were allocated into 4 experimental groups based on their milk yield and body weight. One of the groups served as a control (C) and was fed with a basal concentrate diet, whereas the other three groups were offered the same diet further supplemented with hesperidin (hesperidin, TSI Europe $\mathrm{NV}$, Belgium) at $6000 \mathrm{mg} / \mathrm{kg}$ concentrated feed $(\mathrm{H})$, or naringin (naringin hydrate 98\%, Alfa Aesar GmbH \& Co KG, Germany) at $6000 \mathrm{mg} / \mathrm{kg}$ concentrated feed $(\mathrm{N})$, or a-tocopheryl acetate (DSM Nutritional Products Hellas, Greece) at $200 \mathrm{mg} / \mathrm{kg}$ concentrated feed (VE). Methods used in the present experiment were approved by the bioethical committee of the Agricultural University of Athens (Permit Number: 23/20032013) under the guidelines of "Council Directive 2010/63/EU on the protection of animals used for scientific purposes".

\section{Milk samples and yoghurt preparation}

Animals were milked twice a day at 6 am and $6 \mathrm{pm}$ by a milking machine. Individual milk samples were collected the day before the beginning and at the 7th, 14th, 21st and 28th day of the experiment and obtained after mixing the volume of milk collected during the morning and evening milking. Individual traditional Greek yoghurt samples were separately manufactured by milk collected from each ewe during the sampling days, apart from day 14 due to technical reasons. The main stages of yoghurt production were: collection and filtration of raw ovine milk, heating to $95^{\circ} \mathrm{C}$ for $15 \mathrm{~min}$ without homogenization, transfer to closed $250 \mathrm{ml}$ cups, cooling to $45-50^{\circ} \mathrm{C}$, inoculation and mixing with $2 \%$ of a commercial thermophilic starter culture of Streptococcus thermophilus and Lactobacillus delbrueckii subsp. Bulgaricus (Chr. Hansen, Denmark), incubation at $45^{\circ} \mathrm{C}$ for about $3 \mathrm{~h}$ and storage at $5{ }^{\circ} \mathrm{C}[18]$.

\section{Yoghurt quality parameters}

Yoghurt quality parameters were assessed after one day of refrigerated storage. Colour was measured (3 measurements per sample) using a Miniscan XE (HunterLab, Reston, USA) chromameter set on the $\mathrm{L}^{*}$ (lightness), $a^{*}$ (redness), $\mathrm{b}^{*}$ (yellowness) system (CIE 1976, Commission International de l' Eclairage). $\mathrm{pH}$ was determined using a pHM210 standard pHmeter (MeterLab, Radiometer, Denmark). Rheological measurements of yoghurt were implemented with a Shimadzu Testing Instrument, model AGS-500 NG (Shimadzu Corporation, Kyoto, Japan) equipped with $5 \mathrm{~kg}$ load cell. A plunger with a diameter of $25 \mathrm{~mm}$ was attached to the moving crosshead, which moved both downwards and upwards at a speed of $120 \mathrm{~mm} /$ min, was inserted to a depth of $20 \mathrm{~mm}$ below the yoghurt surface. The firmness $(\mathrm{N})$ was calculated from the resulting curve and defined as the height of the peak force during the compression cycle. Syneresis of yoghurt was measured by emptying the contents of the plastic container $(200 \mathrm{~g})$ into a stretched cheese cloth, cutting crosswise into four pieces, draining in a funnel for $24 \mathrm{~h}$ at $4{ }^{\circ} \mathrm{C}$, collecting the amount of whey drained off in a conical bottle and weighing in gram to provide an index of syneresis.
Antioxidant capacity was assessed after 10 and 20 days of refrigerated storage at $4^{\circ} \mathrm{C}$ on the basis of the malondialdehyde (MDA) levels formed during storage. MDA concentration was determined by using a third-order derivative spectrophotometric method [19]. In brief, $2 \mathrm{~g}$ of each yoghurt sample (two sub-samples per ewe) was homogenized (Edmund Buehler 7400 Tuebingen/H04, Germany) in $8 \mathrm{ml}$ of aqueous trichloroacetic acid (TCA) $(50 \mathrm{~g} / \mathrm{l})$ and $5 \mathrm{ml}$ of butylated hydroxytoluene (BHT) in hexane $(8 \mathrm{~g} / \mathrm{l})$, and the mixture was centrifuged for $3 \mathrm{~min}$ at $3000 \times \mathrm{g}$. The top hexane layer was discarded, and a $2.5 \mathrm{ml}$ of aliquot from the bottom layer was mixed with $1.5 \mathrm{ml}$ of aqueous 2-thiobarbituric acid (TBA) (8g/l) and further incubated at $70^{\circ} \mathrm{C}$ for $30 \mathrm{~min}$. Following incubation, the mixture was cooled under tap water and submitted to third-order derivative (3D) spectrophotometry (Hitachi U3010 Spectrophotometer) in the range of 500-550 $\mathrm{nm}$. The concentration of MDA ( $\mathrm{ng} / \mathrm{ml} \mathrm{milk)} \mathrm{was}$ calculated on the basis of the height of the third-order derivative peak at $521.5 \mathrm{~nm}$ by referring to the slope and intercept data of the computed least-squares fit of standard calibration curve prepared using 1,1,3,3-tetraethoxypropane (TEP), the MDA precursor.

\section{Statistical analysis}

The experimental unit was the animal since it was the smallest unit upon which, either the treatment was applied or the measurements were made. Data were subjected to repeated measures analysis of variance using the MIXED procedure of SAS software [20], with dietary treatment as fixed effect and the sampling day as the repeated factor. Significant differences were tested at 0.05 significance level and results are presented as least square means \pm s.e.m.

\section{Results}

No significant effects of hesperidin, naringin or vitamin E dietary supplementation on yoghurt quality parameters were observed. As shown in Table 1, quality characteristics of yoghurt manufactured by ewe milk that was individually collected after 7, 21 and 28 days of flavonoids dietary inclusion were not significantly different among the experimental groups. Values for colour parameters $\left(\mathrm{L}, \mathrm{a}^{*}, \mathrm{~b}^{\star}\right)$, $\mathrm{pH}$, firmness and syneresis were not influenced after 7, 21 or 28 days of flavonoids incorporation into dairy ewes' diets. At the same time, no significant effects on MDA values were found in yoghurt manufactured with milk samples collected from ewes after 7, 21 and 28 days of flavonoids dietary supplementation and stored at $4^{\circ} \mathrm{C}$ for 10 and 20 days (Table 2).

\section{Discussion}

There is always a challenge of improving health benefits and technological properties of dairy products. According to the literature, yoghurts inoculated with phenolic extracts display higher antioxidant capacity compared to the controls, possibly through the scavenging of free radicals $[21,22]$. However, as far as the authors are aware, no data exist on the influence of antioxidants' dietary supplementation on yoghurt characteristics manufactured by ewe milk. The available literature is mainly focused on the effects of flavonoids dietary inclusion on milk characteristics of dairy cows. As indicated by the previous researchers, milk quality parameters in dairy cows 
Panagiotis Simitzis (2019) The effects of hesperidin or naringin dietary supplementation on yoghurt quality parameters in dairy ewes - A preliminary study

were not negatively influenced by the inclusion of propolis $[23,24]$ or alfalfa [25] or grape seed and grape marc meal [26] or green tea and curcuma [27] flavonoids extracts in their diets. As already pointed out, no significant effects of hesperidin and naringin dietary supplementation on the quality parameters (colour, $\mathrm{pH}$, firmness and syneresis) of the derived yoghurt were observed. This finding may be partially associated with the fact that yield, composition, coagulation properties and fatty acid profile of sheep milk are not influenced by the incorporation of hesperidin or naringin in the diets of dairy ewes [17]. On the other hand, an improvement of milk oxidative stability is observed both in dairy cows [23,24] and dairy ewes [17] after the addition of flavonoids in their diets. In contrast, no significant effects of hesperidin or naringin dietary supplementation on yoghurt oxidative stability were observed in the present study. Fermentation and postacidification may have negatively affected the antioxidant potential of the examined flavonoids, since they are chemical processes in which enzymes break down organic substances into smaller compounds with different function and value [4]. As indicated in previous studies, the interactions between added bioactive compounds, milk proteins, polysaccharides (such as pectin) and the starter cultures might vary on a case-by-case basis [8], leading to different effects on yoghurt texture parameters [28]. At the same time, it could be suggested that dietary flavonoids supplementation did not affect bacterial growth, since no differences in yoghurt properties and especially $\mathrm{pH}$ values were observed.

Table 1. Effect of hesperidin and naringin on yoghurt characteristics after $0,7,21$ and 28 days of dietary supplementation in dairy ewes

\begin{tabular}{|c|c|c|c|c|c|c|c|}
\hline \multirow{2}{*}{ Day } & \multirow{2}{*}{ Parameter } & \multicolumn{4}{|c|}{ Treatment $^{1}$} & \multirow{2}{*}{ S.E.M. } & \multirow{2}{*}{$P$-value } \\
\hline & & C & $\mathbf{H}$ & $\mathbf{N}$ & $\mathbf{E}$ & & \\
\hline & $\mathrm{L}$ & 95.07 & 94.97 & 95.16 & 94.47 & 0.25 & 0.243 \\
\hline \multirow{5}{*}{0} & Colour $^{2} \mathrm{a}^{*}$ & -2.76 & -2.89 & -2.99 & -3.00 & 0.07 & 0.084 \\
\hline & $\mathrm{b}^{*}$ & 11.46 & 11.33 & 11.84 & 11.58 & 0.35 & 0.790 \\
\hline & $\mathrm{pH}$ & 4.24 & 4.23 & 4.25 & 4.49 & 0.14 & 0.542 \\
\hline & Firmness (N) & 0.87 & 0.90 & 0.84 & 0.68 & 0.08 & 0.095 \\
\hline & Syneresis $(\%)$ & 1.96 & 2.73 & 1.33 & 3.50 & 0.65 & 0.109 \\
\hline \multirow{6}{*}{7} & $\mathrm{~L}$ & 94.93 & 94.91 & 95.22 & 95.05 & 0.32 & 0.888 \\
\hline & Colour a* & -2.81 & -2.73 & -2.84 & -2.71 & 0.07 & 0.565 \\
\hline & $\mathrm{b}^{*}$ & 10.75 & 10.76 & 10.52 & 10.73 & 0.44 & 0.977 \\
\hline & $\mathrm{pH}$ & 4.32 & 4.51 & 4.44 & 4.38 & 0.13 & 0.768 \\
\hline & Firmness $(\mathrm{N})$ & 0.79 & 0.81 & 0.72 & 0.88 & 0.11 & 0.773 \\
\hline & Syneresis $(\%)$ & 2.12 & 2.47 & 1.58 & 3.44 & 0.66 & 0.260 \\
\hline \multirow{6}{*}{21} & $\mathrm{~L}$ & 94.73 & 94.53 & 95.02 & 94.88 & 0.37 & 0.811 \\
\hline & Colour $a^{*}$ & -2.70 & -2.84 & -2.77 & -2.66 & 0.07 & 0.282 \\
\hline & $\mathrm{b}^{*}$ & 10.32 & 11.00 & 10.84 & 10.80 & 0.57 & 0.854 \\
\hline & $\mathrm{pH}$ & 4.30 & 4.19 & 4.18 & 3.94 & 0.23 & 0.720 \\
\hline & Firmness $(\mathrm{N})$ & 0.81 & 0.75 & 0.87 & 0.92 & 0.10 & 0.730 \\
\hline & Syneresis(\%) & 2.22 & 3.43 & 2.99 & 3.41 & 0.93 & 0.768 \\
\hline \multirow{6}{*}{28} & $\mathrm{~L}$ & 94.60 & 94.53 & 94.69 & 94.78 & 0.34 & 0.953 \\
\hline & Colour $\mathrm{a}^{*}$ & -2.81 & -2.67 & -2.84 & -2.79 & 0.08 & 0.435 \\
\hline & $\mathrm{b}^{*}$ & 10.28 & 11.51 & 11.01 & 11.47 & 0.11 & 0.529 \\
\hline & $\mathrm{pH}$ & 4.30 & 4.44 & 4.10 & 4.20 & 0.18 & 0.591 \\
\hline & Firmness $(\mathrm{N})$ & 0.58 & 0.79 & 0.89 & 0.91 & 0.10 & 0.133 \\
\hline & Syneresis(\%) & 2.49 & 3.59 & 3.84 & 2.44 & 0.87 & 0.220 \\
\hline
\end{tabular}

${ }^{1}$ The control group (C) was fed with a commercial basal diet, whereas the other groups consumed the same diet, with the only difference that concentrated feed was uniformly supplemented with hesperidin $(\mathrm{H})(6000 \mathrm{mg} / \mathrm{kg}$ feed $)$ or naringin $(\mathrm{N})(6000 \mathrm{mg} /$ $\mathrm{kg}$ feed) or vitamin E (VE) $\left(200 \mathrm{mg} / \mathrm{kg}\right.$ feed). ${ }^{2} \mathrm{~L}^{*}$; lightness, $\alpha^{*}$; redness, $\mathrm{b}^{*}$; yellowness 
Panagiotis Simitzis (2019) The effects of hesperidin or naringin dietary supplementation on yoghurt quality parameters in dairy ewes - A preliminary study

Table 2. MDAvalues (ng/g) in yoghurt manufactured from milk samples collected the day before, 7,21 and 28 days after hesperidin and naringin dietary supplementation.

\begin{tabular}{|c|c|c|c|c|c|c|c|}
\hline \multirow{2}{*}{$\begin{array}{l}\text { Milk Sampling } \\
\text { (days) }\end{array}$} & \multirow{2}{*}{$\begin{array}{c}\text { Refrigerated Storage } \\
\text { (days) }\end{array}$} & \multicolumn{4}{|c|}{ Treatment $^{1}$} & \multirow{2}{*}{ S.E.M. } & \multirow{2}{*}{$P$-value } \\
\hline & & C & $\mathbf{H}$ & $\mathbf{N}$ & VE & & \\
\hline \multirow{3}{*}{0} & 10 & 2.96 & 2.76 & 2.65 & 2.88 & 0.23 & \multirow{3}{*}{0.907} \\
\hline & & & & & & & \\
\hline & 20 & 3.35 & 3.24 & 3.28 & 3.16 & 0.23 & \\
\hline \multirow{3}{*}{7} & 10 & 2.19 & 2.05 & 1.83 & 1.82 & 0.27 & \multirow{3}{*}{0.484} \\
\hline & & & & & & & \\
\hline & 20 & 3.25 & 2.63 & 2.83 & 3.23 & 0.27 & \\
\hline \multirow{3}{*}{21} & 10 & 2.32 & 2.43 & 2.87 & 2.90 & 0.23 & \multirow{3}{*}{0.902} \\
\hline & & & & & & & \\
\hline & 20 & 2.90 & 2.75 & 3.36 & 3.18 & 0.23 & \\
\hline \multirow{3}{*}{28} & 10 & 3.87 & 4.23 & 3.80 & 3.50 & 0.36 & \multirow{3}{*}{0.468} \\
\hline & & & & & & & \\
\hline & 20 & 4.21 & 4.35 & 4.99 & 4.19 & 0.36 & \\
\hline
\end{tabular}

${ }^{1}$ The control group (C) was fed with a commercial basal diet, whereas the other groups consumed the same diet, with the only difference that concentrated feed was uniformly supplemented with hesperidin $(\mathrm{H})(6000 \mathrm{mg} / \mathrm{kg}$ feed $)$ or naringin $(\mathrm{N})(6000 \mathrm{mg} / \mathrm{kg}$ feed $)$ or vitamin E $(\mathrm{VE})$ (200mg/kg feed).

\section{Conclusions}

As indicated by the results of the present study, dietary supplementation of dairy ewes with flavonoids at the examined levels does not improve yoghurt quality characteristics and oxidative stability.

\section{Funding information}

This research was funded by Hellenic State and European Union, within the framework of the Project "Thalis - The effects of antioxidant's dietary supplementation on animal product quality", MIS 380231.

\section{References}

1. Gahruie HH, Eskandari MH, Mesbahi G, Hanifpour MA (2015) Scientific and technical aspects of yogurt fortification: A review. Food Sci. Human Wellness 4: $1-8$.

2. O'Connell J, Fox P (2001) Significance and applications of phenolic compounds in the production and quality of milk and dairy products: a review. Int Dairy $J 11$ : 103-120.

3. FitzGerald RJ, Murray BA, Walsh DJ (2004) Hypotensive peptides from milk proteins. J Nutr 134: 980S-988S. [crossref]

4. Yildiz F (2009) Development and manufacture of yogurt and other functional dairy products. (1st ed.). CRC press, Taylor and Francis Group: Boca Raton, Florida, USA.

5. Mozaffarian D, Wu JH (2018) Flavonoids, dairy foods, and cardiovascular and metabolic health: a review of emerging biologic pathways. Circ Res 122: 369-384. [crossref]

6. Rodríguez-García C, Sánchez-Quesada C, Gaforio J (2019) Dietary Flavonoids as Cancer Chemopreventive Agents: An Updated Review of Human Studies. Antioxidants 8: 137. [crossref]

7. Hashemi SMB, Amininezhad R, Shirzadinezhad E, Farahani M (2016) The Antimicrobial and Antioxidant Effects of Citrus aurantium L. Flowers (Bahar Narang) Extract in Traditional Yoghurt Stew during Refrigerated Storage. J Food Saf 36: 153-161.

8. Sun-Waterhouse D, Zhou J, Wadhwa SS (2013) Drinking yoghurts with berry polyphenols added before and after fermentation. Food Control 32: 450-460.

9. Sun-Waterhouse D, Zhou J, Wadhwa SS (2012) Effects of adding apple polyphenols before and after fermentation on the properties of drinking yoghurt. Food Bioprocess Tech 5: 2674-2686.
10. Oliveira A, Alexandre EM, Coelho M, Lopes C, Almeida DP et al. (2015) Incorporation of strawberries preparation in yoghurt: Impact on phytochemicals and milk proteins. Food Chem 171: 370-378. [crossref]

11. Najgebauer-Lejko D, Sady M, Grega T, Walczycka M (2011) The impact of tea supplementation on microflora, $\mathrm{pH}$ and antioxidant capacity of yoghurt. Int Dairy J 21: 568- 574 .

12. Amirdivani S, Baba AS (2011) Changes in yogurt fermentation characteristics, and antioxidant potential and in vitro inhibition of angiotensin-1 converting enzyme upon the inclusion of peppermint, dill and basil. LWT-Food Sci Technol 44: 14581464.

13. El-Said MM, Haggag HF, El-Din HMF, Gad AS, Azza M.Farahat (2014) Antioxidant activities and physical properties of stirred yoghurt fortified with pomegranate peel extracts. Ann Agric Sci 59: 207-212.

14. Trigueros L, Wojdyło A, Sendra E (2014) Antioxidant activity and proteinpolyphenol interactions in a pomegranate (Punica granatum L.) yogurt. J Agric Food Chem 62: 6417- 6425.

15. Chouchouli V, Kalogeropoulos N, Konteles SJ, Karvela E, Dimitris Makris P et al (2013) Fortification of yoghurts with grape (Vitis vinifera) seed extracts. LWT-Food Sci Technol 53: 522-529.

16. Sun-Waterhouse D, Zhou J, Wadhwa SS (2011) Effects of adding apple polyphenols before and after fermentation on the properties of drinking yoghurt. Food Bioprocess Tech 5: 2674-2686.

17. Simitzis P, Massouras Th, Goliomytis M, Charismiadou M, Moschou K et al. (2019) The effects of hesperidin or naringin dietary supplementation on the milk properties of dairy ewes. J Sci Food Agric 99: 6515-6521. [crossref]

18. Kaminarides S, Stamou P, Massouras T (2007) Comparison of the characteristics of set type yoghurt made from ovine milk of different fat content. Int J Food Sci Technol 42: 1019- 1028.

19. Botsoglou NA, Fletouris DJ, Papageorgiou GE, Vassilopoulos VN, Antonios Mantis J et al. (1994) A rapid, sensitive, and specific thiobarbituric acid method for measuring lipid peroxidation in animal tissues, food, and feedstuff samples. $J$ Agric Food Chem 42: 1931-1937.

20. Sas/Stat (2011) Statistical Analysis Systems, Version 9.3, SAS Institute Inc., Cary, NC.

21. Karaaslan M, Ozden M, Vardin H, Turkoglu H (2011) Phenolic fortification of yogurt using grape and callus extracts. LWT-Food Sci Technol 44: 1065-1072.

22. Alenisan MA, Alqattan HH, Tolbah LS, Shori AB (2017) Antioxidant properties of dairy products fortified with natural additives: A review. J Assoc Arab Univ Basic Appl Sci 24: 101-106.

23. Aguiar SC, Cottica SM, Boeing JS, Samensari RB, Santos GT et al. (2014) Effect of feeding phenolic compounds from propolis extracts to dairy cows on milk production, milk fatty acid composition and the antioxidant capacity of milk. Anim Feed Sci Technol 193: 148-154. 
Panagiotis Simitzis (2019) The effects of hesperidin or naringin dietary supplementation on yoghurt quality parameters in dairy ewes - A preliminary study

24. Santos NW, Yoshimura EH, Machado E, Matumoto-Pintro PT, Paula Montanher F et al. (2016) Antioxidant effects of a propolis extract and vitamin E in blood and milk of dairy cows fed diet containing flaxseed oil. Livestock Sci 191: 132-138.

25. Zhan J, Liu M, Su X, Zhan K, Zhang C et al. (2017) Effects of alfalfa flavonoids on the production performance, immune system, and ruminal fermentation of dairy cows. Asian-Australas J Anim Sci 30: 1416-1424. [crossref]

26. Gessner DK, Koch C, Romberg FJ, Winkler A, Dusel G et al. (2015) The effect of grape seed and grape marc meal extract on milk performance and the expression of genes of endoplasmic reticulum stress and inflammation in the liver of dairy cows in early lactation. J Dairy Sci 98: 8856-8868. [crossref]
27. Winkler A, Gessner DK, Koch C, Romberg FJ, Dusel G et al. (2015) Effects of a plant product consisting of green tea and curcuma extract on milk production and the expression of hepatic genes involved in endoplasmic stress response and inflammation in dairy cows. Arch Anim Nutr 69: 425-441. [crossref]

28. Do Espírito Santo AP, Perego P, Converti A, Oliveira MND (2012) Influence of milk type and addition of passion fruit peel powder on fermentation kinetics, texture profile and bacterial viability in probiotic yoghurts. LWT-Food Sci Technol 47: 393-399.

\section{Citation:}

Panagiotis Simitzis, Theofilos Massouras, Michael Goliomytis, Maria Charismiadou, Katerina Moschou, Christina Economou, Vagelis Papadedes, Sofia Lepesioti and Stelios Deligeorgis (2019) The effects of hesperidin or naringin dietary supplementation on yoghurt quality parameters in dairy ewes - A preliminary study. .Nutr Diet Nutraceuticals Volume 1(1): 1-5. 